\title{
CALCULATION OF HEAT CAPACITY IN MEAT DURING ITS FREEZING CONSIDERING PHASE CHANGE
}

\author{
Yuriy M. Berezovskiy, ${ }^{\star}$ Igor. A. Korolev, Taras A. Sarantsev \\ All-Russian Scientific Research Institute of Refrigeration Industry - \\ Branch of V. M. Gorbatov Federal Research Center for Food Systems of RAS, Moscow, Russia
}

Key words: crystallization, meat freezing, crystallization model, freezing point coordinates

\begin{abstract}
As a consequence of insufficient study of water phase change in meat accompanied by water crystallization, its modeling is currently based on the empirical dependence of the frozen water portion on temperature. Such model does not allow answering a number of questions such as of metrological order, and also of physicochemical interpretation of processes occurring in meat during water crystallization. In this paper, we propose an approach to modeling the phase change process of meat during its freezing on the basis of the phonon theory of Debye crystallization, which allows to obtain physically justified dependences of heat capacity on temperature in the phase change region. The obtained dependences may serve as a simple method for calculating the heat capacity of meat in the temperature range of $113 \mathrm{~K}$ to the cryoscopic temperature of the given meat type, or as a basis for the analysis and correction of factors affecting the meat freezing in the temperature range of the phase change.
\end{abstract}

\section{Introduction}

Most scientists in the field of food refrigeration $[1,2,3,4,5,6]$ believe that the calculated dependence of the specific isobaric heat capacity of food products is subject to the additivity law and may be expressed as follows:

where

$$
c=g_{1} \cdot c_{1}+g_{1} \cdot c_{1}+\ldots+g_{n} \cdot c_{n}
$$

$g_{1} ; g_{2} \ldots g_{\mathrm{n}}$ are mass fractions of the mixture ingredients;

$c_{1} ; c_{2} \ldots c_{n}$ are specific heat capacity factors of the ingredients.

For meat and dairy products, to calculate the specific heat capacity, Latyshev V. P. et al. [5, 6] proposed a temperature dependence of the additive type, where the product is considered as a three-ingredient mixture, i. e. solids, water (ice) and fat:

where

$$
c_{p}=c_{\text {sol }} \cdot \xi_{\text {sol }}+c_{\text {fat }} \cdot \xi_{\text {fat }}+\xi_{\text {wat }}\left(c_{i c e}-L \frac{d}{d t}(\omega)\right)
$$

$c_{p} ; c_{\text {sol }} ; c_{\text {fat }} ; c_{i c e}$ are specific isobaric heat capacities;

$\xi_{\text {sol }} ; \xi_{\text {fat }} ; \xi_{\text {wat }}$ are mass fractions of solids, fat and water, respectively;

$L$ is specific heat of crystallization, $\mathrm{J} / \mathrm{kg}$;

$\omega$ is portion of frozen-out water, $T$ is temperature, $\mathrm{K}$.

All members of the dependencies are empirical, which suggests the need to measure heat capacities of many ingredients, including portions of frozen-out water.

The value of heat capacity in the phase change region is not included in equation (1) due to its general nature. In equation (2), this drawback is eliminated, but the member considering heat capacity of phase change is based on the derivative of the frozen-out water portions, which is determined by empirical methods that do not have a satisfactory physicochemical basis $[3,4,5,11]$. In this regard, difficulties arise in determining the extreme values of heat capacity, as well as in determining the start of melting or the end of freezing.
Recently, several studies were conducted on processes of freezing and thawing, considering their effect on product quality $[11,12,13,14,15,16,17,18,19,20]$.

The method for modeling and analysis of phase change in meat during its freezing proposed in this paper is based on other methods not previously used. Dependence determining for the specific heat capacity proposed by Debye was carried out using the Einstein-Planck dependence obtained for gases. But as shown by Debye with some assumptions, this dependence may also be applied to crystalline bodies. This approach makes it possible to clarify the temperatures of the beginning and ending of the phase change process, as well as to identify energy factors affecting the process.

\section{Materials and methods}

In this work, the experimental basis for modeling the meat freezing process is the results of meat thermophysical characteristics study obtained on NETSCH 204 F1 differential scanning calorimeter (DSC). The ability to increase the reliability of measurements of meat specific heat capacity by differential scanning calorimetry methods is realized by $\tau-R$ correction [9]. A comparison of the results of such measurements with similar measurements using an adiabatic instrument [5,7] indicates almost complete agreement.

Determination of the meat cryoscopic temperature is carried out by OSKR-1 osmometer cryoscope, which is included in the State Register of Measuring Instruments of the Russian Federation with No. 42519-09. Specification of OSKR-1 are shown in Table 1.

Table 1. Main specifications of OSKR-1

\begin{tabular}{l|l} 
Parameter & Tolerance \\
\hline
\end{tabular}

Range of freezing temperature measurement: $\quad 0$ to $-3.720^{\circ} \mathrm{C}$ General absolute tolerance in temperature measurement

- in the range of 0 to $-0.930^{\circ} \mathrm{C}$ : $\pm 0.002^{\circ} \mathrm{C}$

- in the range of -0.930 to $-3.720^{\circ} \mathrm{C}$ : $\quad \pm 0.010{ }^{\circ} \mathrm{C}$

\begin{tabular}{l|l|} 
Sample volume, not less than: & $0.3 \mathrm{ml}$
\end{tabular} 
The research objects were:

1) NOR grade beef. Beef samples were obtained at meat processing plants in the Moscow region immediately after slaughter and production. Samples were taken from M. longissimus dorsi;

2) Pork samples were obtained at meat processing plants in the Moscow region immediately after slaughter and production. Samples were taken from pork M. longissimus dorsi. All samples were of NOR grade.

The study of the phase change in meat near and at the cryoscopic point in theoretical terms is associated with the singularity of modeling functions. Whereas in meat, this temperature range is the least studied regarding the physicochemical parameters of freezing process [10]. The proposed model of the meat freezing process based on the Debye quantum-mechanical approach (phonon theory of thermal radiation $[12,13]$ ) allows the analysis to be carried out step-by-step over small temperature ranges near and at the cryoscopic temperature point.

\section{Results and discussion}

Equation of the crystal internal energy according to the Debye hypothesis is as follows:

where

$$
U=\frac{3 N h v}{2}+3 N h v \frac{e^{-h v / k T}}{1-e^{-h v / k T}},
$$

$U$ is internal energy of a crystal atom, J;

$N$ is the number of atoms in the ice crystal $\left(N \sim 10^{25} \mathrm{~kg}^{-1}\right)$ in the Einstein-Planck equation, which was converted by Debye to apply the description of the crystalline body energy;

$h$ is the Planck constant, $\mathrm{h}=6.626 \cdot 10^{-34} \mathrm{~J} \cdot \mathrm{s}$;

$v$ is the frequency of atom vibrations in the crystal, $\mathrm{s}^{-1}$;

$k$ is the Boltzmann constant, $\mathrm{J} / \mathrm{K}$;

$T$ is the temperature by the Kelvin scale.

It is advisable to consider the energy of the crystallization process in the accepted interpretation as a function, the argument of which is the temperature deviation from the cryoscopic point, i. e. $\left(\mathrm{T}_{\mathrm{kr}}-\mathrm{T}\right)$. Then the equation (1) is as follows:

where:

$$
\begin{aligned}
U= & \frac{3 N h \nu}{2}+3 N h v \frac{e^{-h v / k\left(T_{k r}-T\right)}}{1-e^{-h v / k\left(T_{k r}-T\right)}}= \\
& =\frac{3 N h \nu}{2}+3 N h v \cdot \frac{e^{-\theta / \psi}}{1-e^{-\theta / \psi}},
\end{aligned}
$$

$\theta=h v / k ;$ and $\left(T_{k r}-T\right)=\psi$.

$\theta$ is a coefficient in degrees; in Debye's work it is called the characteristic temperature [12].

The heat capacity of the test sample is the derivative of (4) with respect to $\psi$. Considering that, for small values of $\psi$ near the cryoscopic point, $\mathrm{e}^{-(\theta / \psi)}<<1$, we will have

where

$$
c=3 N k \cdot\left(\frac{\theta}{\psi}\right)^{2} \cdot e^{-\frac{\theta}{\psi}}
$$

$N$ is the number of ice crystallization centers per mass unit of the product, $\mathrm{N}=10^{25}$, it is measured in $\mathrm{kg}^{-1}$; $\mu$ is the coefficient of the order of unity correcting the $N$ for a certain type of meat (beef, pork, etc.);

$T$ is the temperature by the Kelvin scale, $\mathrm{K}$.

As will be shown below, equation (5) is valid in the following interval:

$242<\mathrm{T}<\mathrm{T}_{\mathrm{kr}}$ by the Kelvin scale and $\mathrm{t}_{\mathrm{kr}}<<\mathrm{t}<<0{ }^{\circ} \mathrm{C}$;

$$
0<\psi<273 \mathrm{~K} \text {. }
$$

In the research laboratory of food products thermophysical properties, the All-Russian Scientific Research Institute of Refrigeration Industry, the analysis was carried out of the phase change process when freezing beef and pork using transformed dependence (5). In the expanded semi-empirical version, the equation is as follows (6):

$$
c=\mu \cdot N \cdot k \cdot\left(\frac{\theta}{T_{k r}-T+\delta}\right)^{2} e^{-\left(\frac{\theta}{T_{k r}-T+\delta}\right)}+B \cdot 10^{-3} \cdot T,
$$

where

$\delta$ is the coefficient for deviation of the temperature of the water crystallization onset (during the process of transformation into ice) from the temperature of the heat capacity peak in the process of phase change, $\mathrm{K}$;

$B$ is an empirical coefficient in $\mathrm{J} / \mathrm{kg} \cdot \mathrm{K}^{2}$ characterizing the contribution of heat capacity of anhydrous ingredients.

Dependence (6) allows to determine the heat capacity of meat in the phase change region with an error of $\pm 3.5 \%$ in the temperature range of $242 \leq \mathrm{T} \leq \mathrm{T}_{\mathrm{k}}$. The peaks of the calculated curves correspond to the maximum experimental values of meat heat capacities: $300 \mathrm{~kJ} / \mathrm{kg} \cdot \mathrm{K}$ and $240 \mathrm{~kJ} / \mathrm{kg} \cdot \mathrm{K}$ for beef and pork, respectively. The deviation of the temperature of the maximum calculated heat capacity from the corresponding maximum of the experimental heat capacity is $0.1 \mathrm{~K}$ both for beef and pork. Meat moisture is significant for determining heat capacity and must be kept within the limits specified for given meat grade.

The values of $\mu, \theta, \delta$ coefficients and cryoscopic temperature $T_{k}$ for beef and pork of NOR grade are shown in Table 2 .

$c_{\max }$ is the maximum value of heat capacity at the peak of phase change, $\mathrm{kJ} / \mathrm{kg} \cdot \mathrm{K}$.

Table 2. The values of the coefficients for equation (6)

\begin{tabular}{|c|c|c|c|c|c|c|}
\hline Meat type & $\boldsymbol{\theta}$ & $T_{k r}$ & $\boldsymbol{\mu}$ & $\boldsymbol{\delta}$ & $B$ & $c_{\max }$ \\
\hline Beef & $\mathbf{0 . 5 5}$ & $\mathbf{2 7 2 . 1 9}$ & $\mathbf{1 . 3 3 5}$ & $\mathbf{0 . 3 5}$ & $\mathbf{7 . 5 \cdot 1 0 ^ { - 3 }}$ & 300 \\
\hline Pork & $\mathbf{0 . 7 1}$ & 272.0 & $\mathbf{1 . 0 6}$ & $\mathbf{0 . 5}$ & $\mathbf{6 . 7} \cdot \mathbf{1 0}^{-3}$ & $\mathbf{2 4 0}$ \\
\hline
\end{tabular}

In the rest of the temperature range of $110 \mathrm{~K}$ to $242 \mathrm{~K}$, the deviations of the calculated values of heat capacity do not exceed 3\%. The tabular values of $\delta$ parameter slightly exceed the experimentally obtained data corresponding to the curve segment for the crystallization onset, i. e. the experimental value is $\delta=0,01 \mathrm{~K}$. In our opinion, such deviation from the theoretical curve may be due the methods and accuracy of temperature measurement in a frozen product during crystallization.

The proposed interpretation of the model for water crystallization in meat allows to identify the relationship 


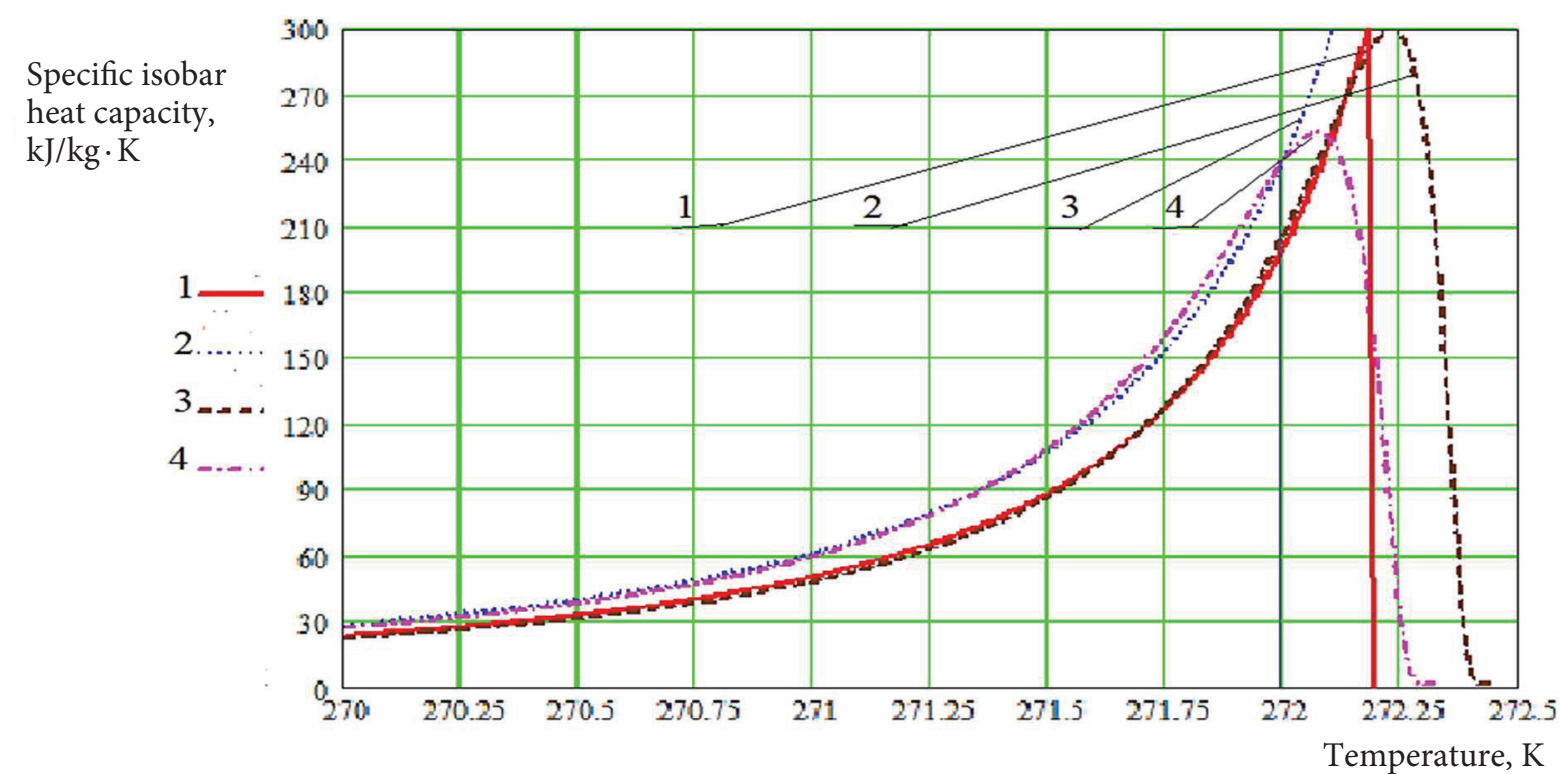

Figure 1. Shows the diagrams for obtained by differential scanning calorimetry (DSC) using DSC204 F1 device (curves 1 and 3 ) and diagrams obtained by calculation according to equation (6) (curve 2 - beef, curve 4 - pork).

between the heat capacity of meat and the characteristic Debye temperature $(\theta)$, i. e. the frequency of phonon waves. In addition, it seems to be possible to assess the degree of water crystallinity in meat characterized by the $N \cdot \mu$ parameter.

For determination of heat capacity of NOR grade beef and pork in the temperature range of phase change, equations (7) and (8) are proposed, respectively:

$$
\begin{gathered}
C_{\text {beef }}=\frac{185,47}{\left(T_{k r}-T+0,777\right)}+7,4 \cdot 10^{-3} \cdot T ; \\
C_{\text {pork }}=\frac{227,7}{\left(T_{k r}-T+0,777\right)}+6,66 \cdot 10^{-3} \cdot T
\end{gathered}
$$

To apply these equations, it is sufficient to determine only the cryoscopic temperature of the meat. In the indicated temperature range, the deviation of the heat capacity calculated values does not exceed $\pm 3.5 \%$.

In [14], the results of comparing the experimental and calculated determinations of the cryoscopic temperature depending on beef moisture content are presented (9). In the range of moisture content of $0.6 \leq \mathrm{w} \leq 0.8$ with an error of $\pm 0.2 \mathrm{~K}$

$$
T_{k r}=256,64+35,0 \cdot w-19,3 \cdot w^{2}
$$

Equation (9) allows to conclude that the heat capacity of the studied beef, in fact, depends only on moisture content and temperature.

Such a fairly accurate determination of the heat capacity values when compared with the curves obtained experimentally by the DSC method using the $\tau$-R correction allows to identify the points of the phase change termination and continued cooling of meat with water contained in it that is not subject to freezing.

The experimental DSC curves of beef and pork heat capacity shown in Figures 2 and 3 have a noticeable break point, i. e. sharp change in curvature. At these points, the interpolation curves describing the experimental ones with high accuracy disagree with the latter. In the temperature range of $110 \mathrm{~K}$ to $242 \mathrm{~K}$, experimental DSC curves are described by polynomials (9) and (10) with the high accuracy of $\pm 3 \%$.

The coordinates of the intersection points (see Figures 2 and 3):

- for beef $243 \mathrm{~K}$;

- for pork $242 \mathrm{~K}$.

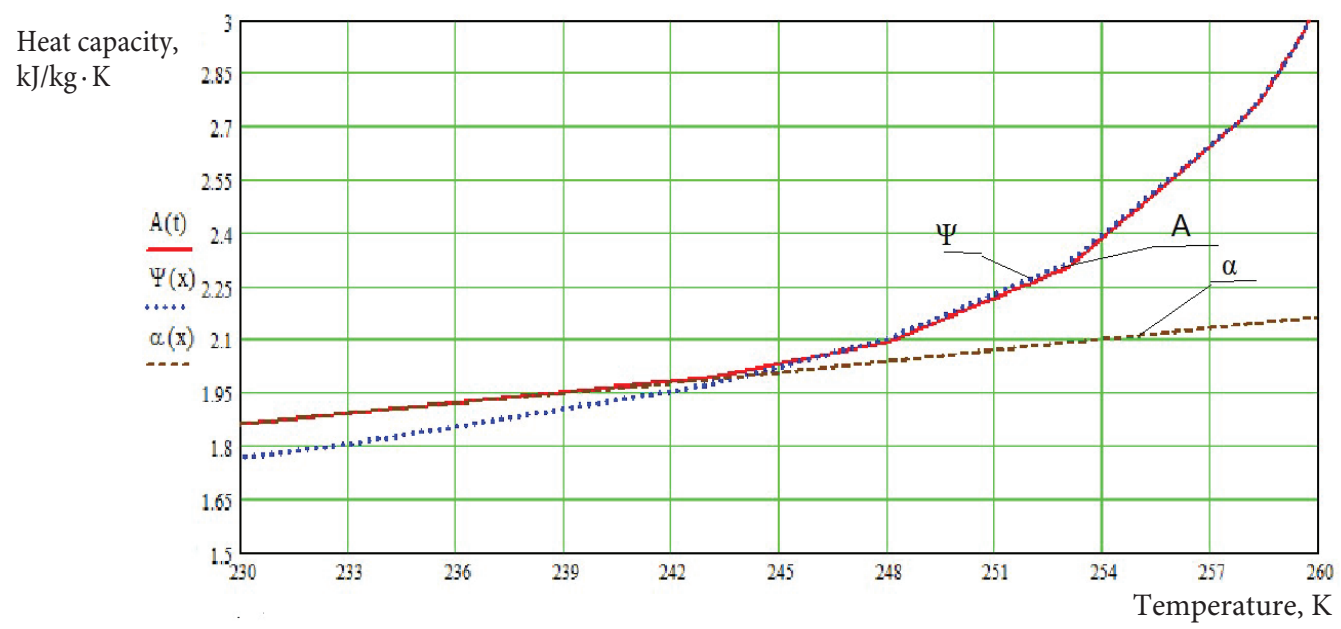

Figure 2. Beef heat capacity in the temperature region of the transition from crystallization ending to cooling of the frozen product: A is the DSC curve; $\alpha$ is the calculated heat capacity curve below the phase change region; $\psi$ is the calculated curve of the phase change region 


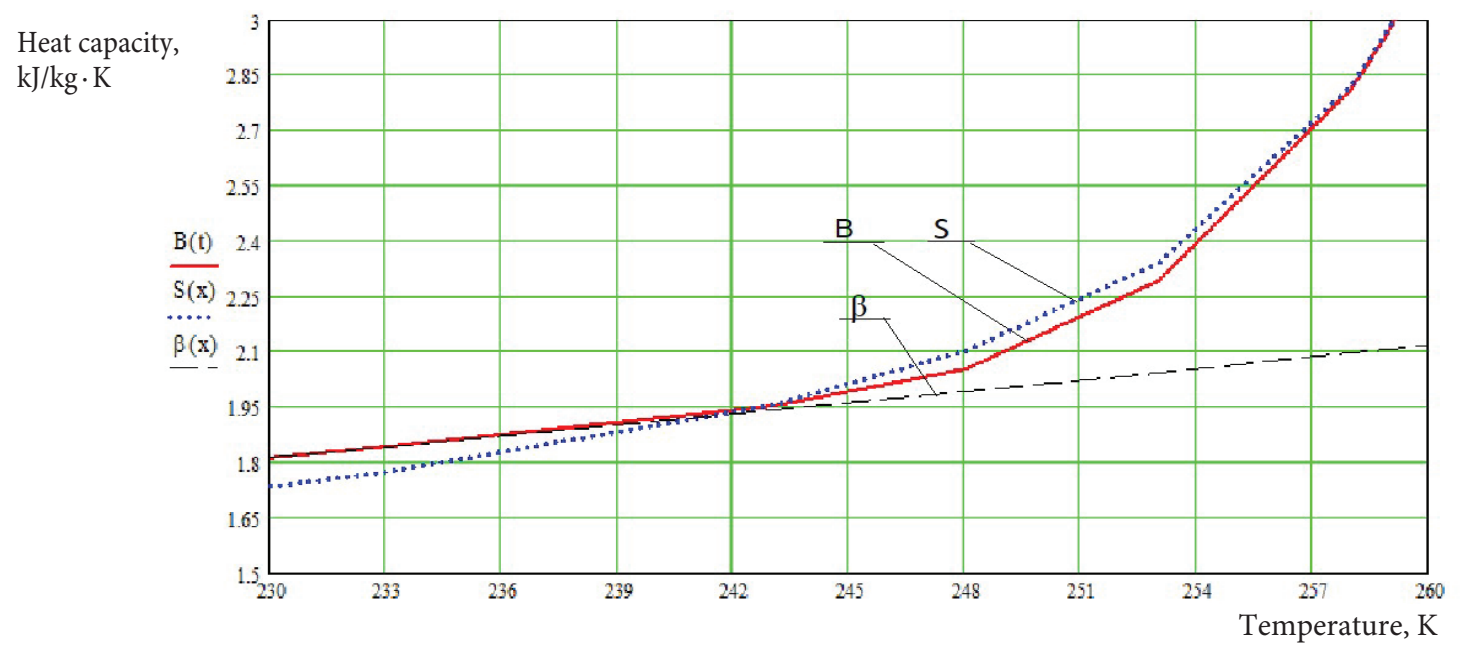

Figure 3. Pork heat capacity in the temperature region of the transition from crystallization ending to cooling of the frozen product: B is the DSC curve; $S$ is the calculated heat capacity curve of the phase change region; $\beta$ is the calculated curve below the phase change region

Dependences for heat capacities:

beef

$$
C_{\text {beef }}=0,548+1,85 \cdot 10^{-3} \cdot T+1,68 \cdot 10^{-5} \cdot T^{2}
$$

pork

$$
\begin{aligned}
C_{\text {pork }} & =0,7+0,15 \cdot 10^{-3} \cdot T+1,9 \cdot 10^{-5} \cdot T^{2}+ \\
& +0,55 \cdot 10^{-8} \cdot T^{3}+0,1 \cdot 10^{-11} \cdot T^{4}
\end{aligned}
$$

In Figures 2 and 3, these dependences are represented by $\alpha$ and $\beta$ curves:

It must be considered that the use of the indicated equations is possible only within the temperature range of $113 K \leq T \leq T_{\text {Ophase }}$ K; $T_{\text {Ophase }}$ is the temperature of the phase change ending.

\section{Conclusion}

Semi-empirical transformation of the Debye theoretical provisions on the process of solids crystallization allowing to determine the dependence of their heat capacity on temperature made it possible to obtain the calculated dependences of beef and pork heat capacity in the temperature range of phase change during meat freezing.

It is shown that the transition from phase change during meat freezing to stationary meat cooling has clear boundaries with stationary coordinates. These coordinates are determined for beef and pork of NOR grades.

It is shown that beef and pork heat capacity may be calculated based on only two thermophysical characteristics of meat, i. e. moisture content and cryoscopic temperature.

\section{REFERENCES}

1. Ginsburg, A.S., Gromov, M.A., Krasovskaya, G.I. (1990). Thermophysical characteristics of food. Moscow: Agropromizdat. 289 p. (In Russian)

2. Postolskiy, Ya., Gruda, Z. (1970). Food freezing. Moscow: Food industry. -607 p. (In Russian)

3. Chizhov, G.B. (1979). Thermophysical processes in food refrigeration technology. Moscow: Food industry. - 272 p. (In Russian)

4. Rogov, I.A., Babakin, B.S., Fatykhov, Yu.A. (2005). Cryoseparation of raw materials of biological origin. Ryazan: Our time. 287 p. ISBN 5-9841200-5-4 (In Russian)

5. Latyshev, V.P., Tsyrulnikova, N.A. (1992). Recommended reference materials for thermal calculations of food products. Moscow: VNIKHI. - 86 p. (In Russian)

6. Almasi, E., Erdeli, L., Sharoi, E. (1981). Rapid food freezing. Moscow: Light and food industry. -408 p. (In Russian)

7. Drebushak, V.A., Shvedenkov, G. Yu. (2003). Thermal analysis. Novosibirsk: Novosibirsk State University - 114 p. (In Russian) 8. Uenlandt, U. (1978). Thermal analysis methods. Moscow: MIR. -526 p.

9. Höhne, G. W., Hemminger, W.F., Flammersheim, H.-J. (2003). Differential Scanning Calorimetry. Springer Verlag Berlin Heidelberg GmbH. - 298 p. ISBN: 978-3-662-06710-9, https://doi. org/10.1007/978-3-662-06710-9

10. Dibirasulaev, M.A., Belozerov, G.A., Dibirasulaev, D.M., Orlovsky, D.E. (2016). Effect of subcryoscopic storage temperature on the quantity of frozen-out water in NOR and DFD beef. Theory and practice of meat processing, 1(2), 18-25. https://doi. org/10.21323/2414-438X-2016-1-2-18-25 (In Russian) 11. Yancheva, M., Dromenko, O., Potapov, V., Grinchenko, 0. Zhelieva, T. (2018). Development of a physical-mathematical model for the process of crystallization of meat systems. EasternEuropean Journal of Enterprise Technologies, 1(11(91), 50-55. https://doi.org/10.15587/1729-4061.2018.120793
12. Phan Q. T. (2014). Freezing time formulas for foods with low moisture content, low freezing point and for cryogenic freezing. Journal of Food Engineering, 127, 85-92. https://doi. org/10.1016/j.jfoodeng.2013.12.007

13. Miller, D.K., Kim, H.-W, Lee, Y., Kim, Y. H. B. (2016). Effects of soy hull fibers and freezing on quality attributes of beef patties. Meat Science, 112, 112-176. https://doi.org/10.1016/j.meatsci.2015.08.168

14. Choe, J.-H., Stuart, A., Kim, Y.H. B. (2016). Effect of different aging temperatures prior to freezing on meat quality attributes of frozen/ thawed lamb loins. Meat Science, 116, 158-164. https://doi.org/10.1016/j.meatsci.2016.02.014

15. Castro-Giráldez, M., Balaguer, N., Hinarejos, E., Fito, P.J. (2014). Thermodynamic approach of meat freezing process. Innovative Food Science \& Emerging Technologies, 23, 138-145. https://doi.org/10.1016/j.ifset.2014.03.007

16. Kim, Y.H.B., Liesse, C., Choe, J., Kemp, R. (2015). Effect of different freezing/thawing methods on meat quality characteristics of pre-agent lamb-loins. Meat Science, 101, 137-138. https://doi.org/10.1016/j.meatsci.2014.09.090

17. Yancheva, M., Dromenko, 0. ., Potapov, V., Grinchenko, 0. Zhelieva, T. (2018). Study of influence of freezing - defrosting on thermophysical properties of meat systems. EUREKA: Life Sciences, 1, 32-38. https://doi.org/10.21303/25045695.2018.00537

18. Kozheurov, V.A. (1973). Statistical thermodynamics. Moscow: Metallurgy. - 176 p. (In Russian)

19. Budanov, V.V., Maksimov, A.I. (2007). Chemical thermodynamics. Moscow: Akadembook. - 312 p. (In Russian)

20. Berezovskiy, Yu. M., Korolev, I.A., Agafonkina, I.V., Sarantsev, T.A. (2018).

21. Investigation of the effect of beef moisture content on the amount of bound moisture with the calorimetric method. Pro- 
ceedings of the Voronezh State University of Engineering Technologies, 80(4(78), 25-29. https://doi.org/10.20914/2310-12022018-4-25-29 (In Russian)
22. Encyclopedia of Food Technology V.16. Technologies for refrigeration processing and storage of food products. Moscow: V. M. Gorbatov Federal Research Center for Food Systems of the Russian Academy of Sciences. -2019. - 334 p. (In Russian)

\section{AUTHOR INFORMATION}

Yuriy M. Berezovskiy - doctor of technical sciences, the head of the laboratory, research laboratory of Food Products Thermophysical Properties, All-Russian Scientific Research Institute of Refrigeration Industry - Branch of V. M. Gorbatov Federal Research Center for Food Systems of the Russian Academy of Sciences 127422, Moscow, Kostyakova str. 12, Tel.: +7-909-685-49-83, E-mail: birjuza1@mail.ru

ORCID: https://orcid.org/0000-0003-1002-2580

${ }^{*}$ corresponding author

Igor A. Korolev - junior researcher, research laboratory of Food Products Thermophysical Properties, All-Russian Scientific Research Institute of Refrigeration Industry- Branch of V. M. Gorbatov Federal Research Center for Food Systems of the Russian Academy of Sciences 127422, Moscow, Kostyakova str. 12, Tel.: +7-916-423-42-17, E-mail: korolev.vnihi@mail.ru ORCID: https://orcid.org/0000-0003-3166-2827

Taras A. Sarantsev - research engineer, research laboratory of Food Products Thermophysical Properties, All-Russian Scientific Research Institute of Refrigeration Industry- Branch of V. M. Gorbatov Federal Research Center for Food Systems of the Russian Academy of Sciences 127422, Moscow, Kostyakova str. 12, Tel.: +7-915-282-18-24, E-mail: codyjeps@gmail.com

ORCID: https://orcid.org/0000-0001-9755-3047

All authors are responsible for the work and data presented.

All authors made an equal contribution to the work.

The authors were equally involved in writing the manuscript and are equally responsible for plagiarism.

The authors declare no conflict of interest.

Received 03.12.2019 Accepted in revised 18.03.2020 Accepted for publication 25.03.2020 